\title{
Ecocardiografía transesofágica intraoperatoria en reparos valvulares aórticos
}

Iván Iglesias*

Carolina Cabrera**

*Western University. London Health Sciences Centre (LHSC), Canadá

**Universidad de Valparaíso, Chile

Recibido: 22/02/2021

Aceptado: 23/02/2021

En línea: 30/04/2021
Correspondencia

Iván Iglesias MD

ecoperioperatorio@gmail.com

Citar como: Iglesias I, Cabrera C, Ecocardiografía transesofágica intraoperatoria en reparos valvulares aórticos. Rev Ecocar Pract (RETIC). 2021 (Abril); 4 (1): $50-52$. doi: 10.37615/retic.v4n1a14.

Cite this as: Iglesias I, Cabrera C, Intraoperatory transesophageal echocardiography in aortic valve repair. Rev Ecocar Pract (RETIC). 2021 (Abril); 4 (1): $50-52$. doi: 10.37615/retic.v4n1a14

\section{Palabras clave}

$\triangleright$ Válvula aórtica

$\triangleright$ Reparación valvular

\section{Keywords}

$\triangleright$ Aortic valve

$\triangleright$ Valve repair

\section{RESUMEN}

El éxito de la plastía de la válvula aortica va a depender de la adecuada evaluación de todos los elementos del aparato aórtico y reconocer los factores que causan la regurgitación. Se destaca el rol del eco transesofágico

\section{ABSTRACT}

The success of the aortic valve plasty will depend on the adequate evaluation of all the elements of the aortic apparatus and the recognition of the factors that cause regurgitation. The role of the transesophageal echo is highlighted
La práctica de cirugías de reparo valvular ha ganado espacio debido al deseo de evitar las complicaciones relacionadas con las prótesis valvulares. Un mejor entendimiento de la anatomía y función de la válvula aórtica y la disponibilidad de ecocardiografía transesofágica intraoperatoria (ETEI) han permitido una gran evolución en las técnicas de preservación valvular aórtica ${ }^{(1)}$. La ETEl ha evolucionado a una nueva subespecialidad: ecocardiografía quirúrgica (Tabla 1).

1. Es estructural, es decir se enfoca en revisar las estructuras que se van a
reparar
2. Sistémica, es decir debe revisarse todo de manera organizada y
consistente
3. Funcional, es decir, se determina el impacto funcional de los hallazgos
4. Operacional, es decir ayuda a entender qué debe hacerse para reparar el
problema
5. Responsable, es decir, que los hallazgos se comprueban de inmediato en
la sala de operaciones
6. Comprometida, es decir, el ecocardiografista entiende la técnica
quirúrgica y ayuda a que el resultado de la cirugía sea satisfactorio

Tabla 1. Características de la ecocardiografía quirúrgica. Definición y tabla original del autor.

\section{Anatomía Funcional Valvular Aórtica}

La válvula aórtica debe verse como una unidad funcional que comprende: unión ventrículo-aórtica y anillo valvular, senos de Valsalva, valvas aórticas y la unión sinotubular.
El anillo aórtico, las valvas y la unión sinotubular tienen un papel predominante en mantener la competencia valvular aórtica. Los senos de Valsalva no juegan un papel directo en la competencia valvular(1).

En las Figuras 1-5 se observan dichos elementos y los parámetros a medir en la raíz aórtica.

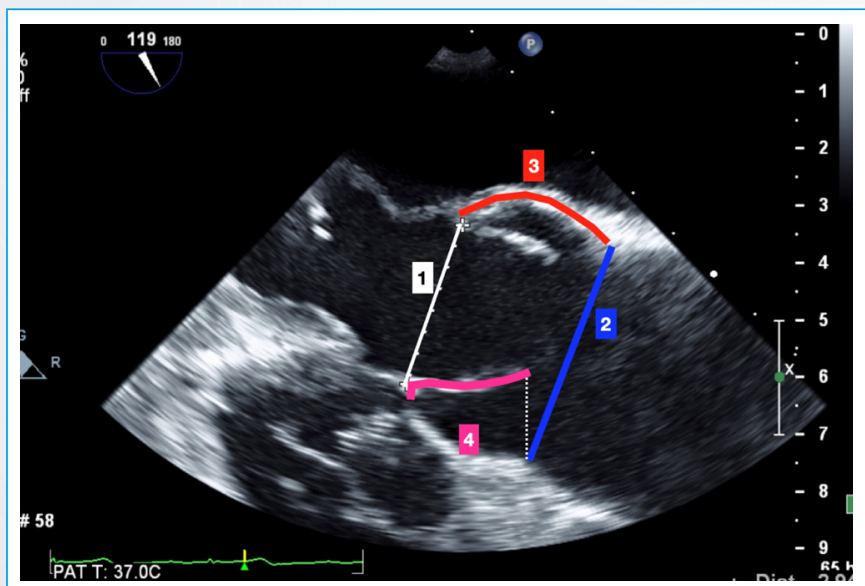

Figura 1. Componentes de la unidad valvular aórtica: 1 unión ventrículo arterial y anillo valvular; 2 unión sinotubular; 3 paredes de los senos de Valsalva; 4 valvas insertadas desde el anillo hasta debajo de la unión sinotubular y con su porción libre coaptando en el medio de la unidad valvular. La unión sinotubular, el anillo valvulary las valvas son los elementos más importantes para la competencia valvular 


\section{- Trukipedia Truco 02}

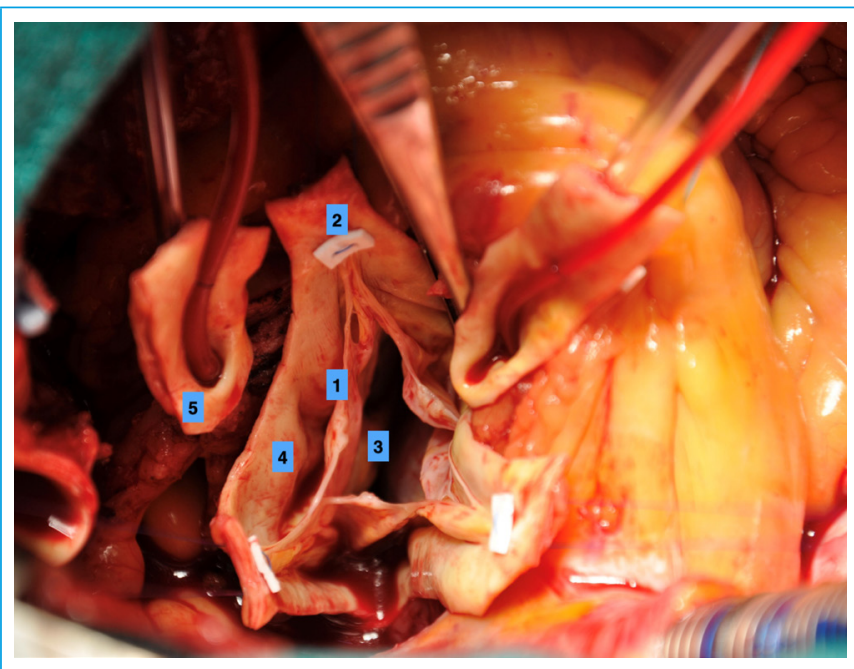

Figura 2. Foto intraoperatoria de una raiz aórtica que ha sido disecada y preparada para reparo. 1 es el borde libre valvar, 2 la comisura, 3 la unión caudal de la valva que forma parte del anillo valvular, 4 pared del seno de Valsalva y 5 botón coronario izquierdo

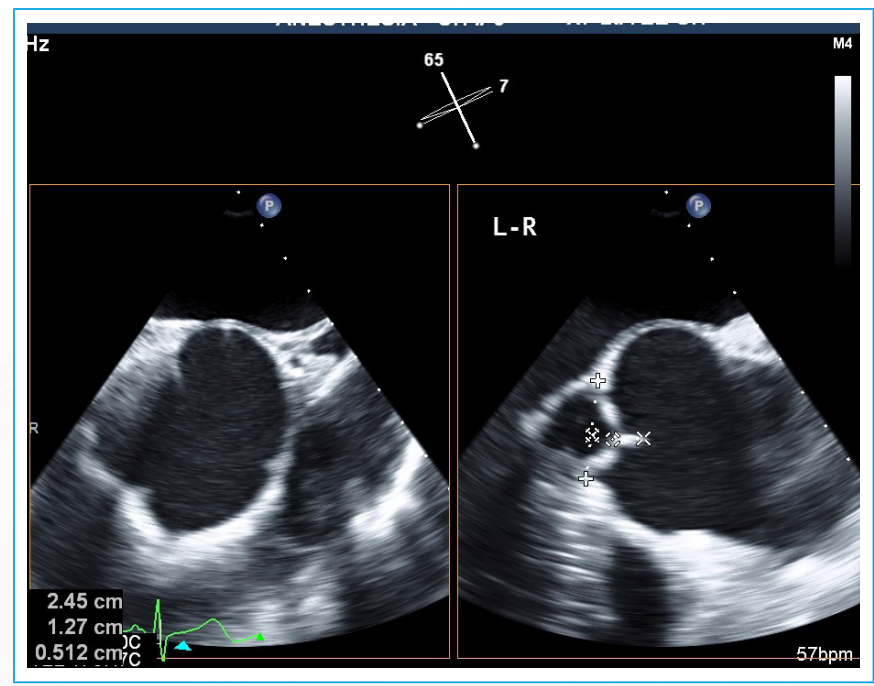

Figura 3. Imagen en planos ortogonales (x plane) partiendo de la vista de eje corto de la válvula aórtica a la izquierda. El plano ortogonal se ha puesto entre las valvas coronarias izquierda y derecha ( $L-R$ en el cuadro derecho) y se observa la simetría de coaptación entre las mismas

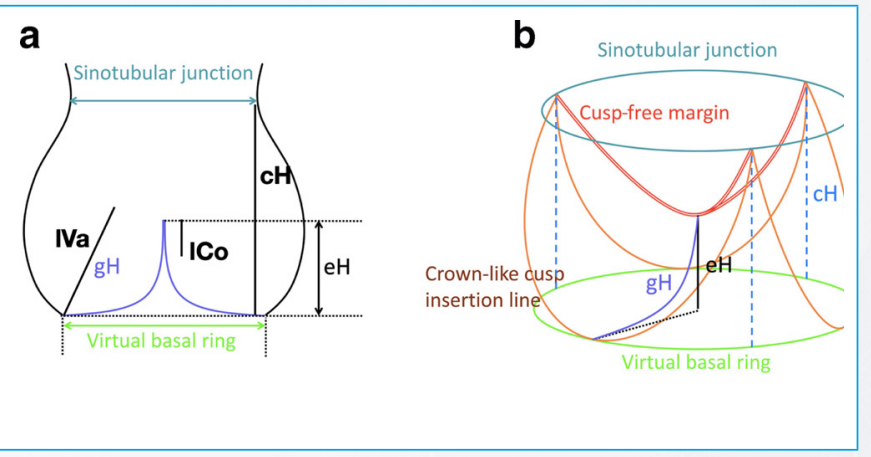

Figura 4. Parámetros medidos en ETEl de la válvula aórtica, algunos se miden en sístole (longitud de la porción libre de la cúspide o valva -IVa-), los otros se miden en diástole (altura efectiva -eH-, longitud de coaptación -ICo-, altura cúspide - $\mathrm{CH}$-, diámetros de la unión sinotubular y del anillo. Tomado y modificado con autorización de: Shäfers H-J; Innov 2019; 14(3):188.

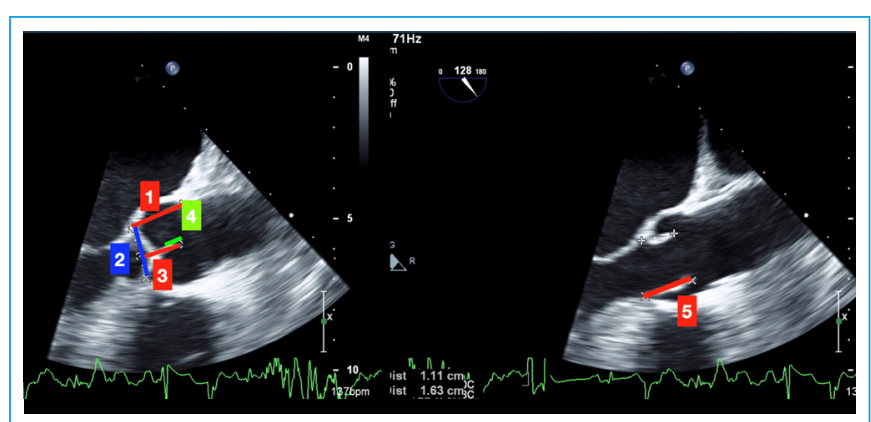

Figura 5. Parámetros a evaluar en la válvula aórtica usando vistas de eje largo 2D. 1: altura de cúspides. 2: anillo valvular, 3: altura de coaptación. 4: longitud de coaptación. 5: longitud de las valvas

Mecanismos de Insuficiencia Aórtica

El Khoury en el 2005 plantea un enfoque de la insuficiencia aórtica (IAo) que entiende la importancia de toda la raíz aórtica en los mecanismos de la misma (Tabla 2) ${ }^{(2)}$.

1. Movilidad normal de las valvas

1A Dilatación de unión sinotubular, asociada a aneurismas de aorta ascendente

1B Dilatación de senos de Valsalva

1C Dilatación de unión ventrículo-arterial (conocido como anillo aórtico)

1D Perforación de tejidos valvares

2. Prolapso de las valvas, movilidad excesiva de las valvas

3. Restricción de las valvas, movilidad restringida de las valvas

Tabla 2. Mecanismos de insuficiencia aórtica basados en los trabajos publicados por Haydar en 1997 y El Khoury en 2005

Ecocardiografía transesofágica y preservación de la válvula aórtica

El uso óptimo de ETEl se da cuando el anestesiólogo ecocardiografista revisa con el cirujano la válvula aórtica en vistas de eje corto y largo esofágicas medias y buscan en conjunto responder dos preguntas básicas:

1. ¿Cuál es la anatomía valvular?,

2. Cuál(es) es(son) el(los) mecanismo(s) de IAo?

En la experiencia del London Health Sciences Centre (LHSC), este es un paso ineludible.

Cuando existe IAo, el ecocardiografista tiene que enfocarse en responder preguntas específicas:

1. ¿Cuál o cuáles mecanismos de IAo existen en el paciente?

2. Los hallazgos de ETEI son favorables para preservar la válvula?

La Tabla 3 muestra hallazgos desfavorables en el reparo valvular y la Tabla 4 muestra los parámetros a evaluar al terminar de reparar la válvula aórtica

- Fenestraciones múltiple

- Fenestraciones produciendo prolapso

- Fenestraciones comisurales

- Cuerpo de la porción libre de las valvas (calvificado, retraído)

- Valvas cortas, porción libre < 16 mm en VA tricúspide, $<19 \mathrm{~mm}$ VA bicúspide

- Anillo valvular dilatado, > 26 mm VA tricúspide, $>29$ mm VA bicúspide

- Antatomía unicúspide

Tabla 3. Hallazgos pre circulación extracorpórea en ETEI 2D que se relacionan con reparos valvulares aórticos menos fáciles o de menor probabilidad de éxito o poca durabilidad. 


\begin{tabular}{|l|l|}
\hline \multicolumn{1}{|c|}{ Parámetro } & \multicolumn{1}{c|}{ Resultado favorable } \\
\hline - Nivel de coaptación & - Es ideal (por encima del anillo) \\
- Insuficiencia residual & - Cero/trazas es ideal \\
- Altura de coaptación & - $8 \mathrm{~mm}$ mínimo \\
- Longitud de coaptación & - $4 \mathrm{~mm}$ mínimo \\
- Gradiente valvular & - Gradiente medio $<10 \mathrm{mmHg}$ \\
\hline
\end{tabular}

Tabla 4. Parámetros a evaluar al terminar de reparar la válvula aórtica

\section{¿Cuál o cuáles mecanismos de IA existen en el paciente?}

Usando imágenes de eje corto comprobamos la anatomía valvular (tricúspide, bicúspide, unicúspide).

Combinando imágenes 2D de eje corto y eje largo con Doppler color revisamos el/los mecanismos de IAo; que pueden deberse a patología de las valvas (perforación, prolapso, retracción), a dilatación de la raíz (anillo, senos de Valsalva, unión sinotubular) o a combinación de factores.

Es importante combinar imágenes de eje corto y eje largo (Xplane) para medir los diámetros del anillo valvular.

Es necesario mencionar que en un porcentaje importante de pacientes existe más de un mecanismo concurrente de IAO, lo cual debe recordarse para, de manera organizada y repetitiva, revisar imágenes 2D y de Doppler color para confirmar si los hallazgos 2D explican el jet de IAo presente en el Doppler color, y, si hay discrepancia, quiere decir casi siempre que hay más de un mecanismo presente o que no se ha comprendido bien el mecanismo de IAo presente.
Se deben usar los botones del ecocardiógrafo para tener la mejor resolución temporal posible, la cual es crítica cuando se usa Doppler color interrogando jets de IAo complejos ${ }^{(3)}$.

En un próximo número ahondaremos los conceptos previamente mencionados, con la finalidad de exponer y comprender de la mejor manera posible la anatomía valvular aórtica y su importancia en la reparación valvular aórtica, así como la valoración ecocardiográfica de la misma.

\section{Ideas para recordar}

- La ecocardiografía transesofágica intraoperatoria es actualmente definida como ecocardiografía quirúrgica.

- La raíz aórtica es una unidad funcional de múltiples elementos.

- El anillo aórtico, la unión sinotubular y las valvas son los elementos determinantes para la competencia valvular.

- El examen ecocardiográfico intraoperatorio de la raíz aórtica le aporta al cirujano información sobre el mecanismo de insuficiencia aórtica.

\section{Bibliografía}

1. Schäfers HJ. The 10 Commandments for Aortic Valve Repair. Innovations (Philadelphia, Pa). 2019;14(3):188-98.

2. El Khoury G, Glineur D, Rubay J, Verhelst R, d'Acoz Y, et al. Functional classification of aortic root/valve abnormalities and their correlation with etiologies and surgical procedures. Current opinion in cardiology. 2005;20(2):115-21.

3. Boodhwani M, El Khoury G. Aortic valve repair: indications and outcomes. Current cardiology reports. 2014;16(6):490. 